\title{
Obsolescence Management for Long-life Contracts: State of the Art and Future Trends
}

\author{
Francisco J. Romero Rojo, Rajkumar Roy and Essam Shehab \\ Decision Engineering Centre, Cranfield University, Cranfield, Bedfordshire, MK43 0AL, UK. \\ \{f.romerorojo;r.roy;e.shehab\}@ cranfield.ac.uk
}

\begin{abstract}
This paper provides a comprehensive literature review on the problem of obsolescence in "sustainment-dominated systems" that require support for many decades. Research on this topic continues to grow as a result of the high impact of obsolescence on the in-service phase of long-term projects. Research on obsolescence also seeks to understand how it can be managed, mitigated and resolved. The paper aims to clarify and classify the different activities that may be included in an obsolescence management planning, taking into account not only electronic components but also other aspects of the system such as mechanical components, software, materials, skills and tooling. The literature review shows that although there are many commercial tools available that support the obsolescence management during the in-service phase of the life cycle of a system, little research has been done to forecast the costs incurred.
\end{abstract}

\section{Keywords}

Obsolescence; Whole Life Cycle; Obsolescence Management; DMSMS; SustainmentDominated Systems

\section{NOMENCLATURE}

BoM Bill of Materials

CADMID Life cycle divided into six phases: Concept, Assessment, Development, Manufacturing, In-Service, Disposal

CFA Contracting for Availability (Availability Contract)

COG Component Obsolescence Group 
COTS Commercial off-the-shelf

DMSMS Diminishing Manufacturing Sources and Materials Shortages

DoD Department of Defence (USA)

FFF Form, Fit and Function Replacement

LOT Life-of-Type

LRU Line-replaceable unit

LTB Life/Last Time Buy

MOCA Mitigation of Obsolescence Cost Analysis

MoD Ministry of Defence (UK)

MOQ Minimum Order Quantity

NPV Net Present Value

OEM Original Equipment Manufacturer

OMP Obsolescence Management Plan

PCN Product Change Notification

PSS Product Service Systems

WLCC Whole Life Cycle Cost

\section{INTRODUCTION}

In sectors such as defence and aerospace, the life-cycle of a sustainment-dominated system can be extended over 20,30 or even more than 40 years. One of the main problems that certainly these systems will face during their lifetime is obsolescence [1]. A component becomes obsolete when the technology that defines it is no longer implemented and therefore that component becomes no longer; available from stock of own spares, procurable, or produced by its supplier or manufacturer [1-5]. Obsolescence can be defined as "the loss or impending loss of original manufacturers of items or suppliers of items or raw materials" [6]. Pecht and Das [3] made a distinction between the 'obsolescence' and 'discontinuance' concepts. They explained that discontinuance, which takes place when the manufacturer stops the production of a component, occurs at a part number or manufacturer specific level, while obsolescence occurs at a technology level. However, in this paper, and widely across industry, the term obsolescence includes discontinuance in the production of a component if there are no other manufacturers for that specific component. 
The continuous and fast technological changes in the last two decades has aggravated the obsolescence of electronic parts [5,7-9]. The components of the sustainment-dominated systems typically go through six life-cycle phases [1,3]: introduction (emergence), growth, maturity, decline, phase-out, and discontinuance (obsolescence). Many authors agree that the life-cycle of many electronic components is shorter than the life-cycle of the system they are built in $[3,5,6,10-15]$. This is the reason why many components are reaching end-of-life and are failing at increased rates in many avionics and military systems $[5,16]$. This obsolescence issue has become one of the main costs in the life cycle of long-field life systems $[3,5,10,12,17,18]$. For instance, the obsolescence issues cost up to $\$ 750$ million annually according to the US Navy estimations [19].

Industrial equipment, avionics and military systems are regarded as "sustainment-dominated systems". Due to the high costs and/or long life times associated with technology insertion and design refresh, these systems often fall behind the technology wave $[17,20,21]$. These systems are characterised by:

$>$ High costs associated with their redesign because of the strict requalification requirements [22]

$>$ Little or no control over their supply chain because of their low production volumes $[4,13,14,22]$

$>$ Field life (sustainment) costs that are much higher than the original purchase price [22]

These systems are designed for long-term sustainment and are usually composed of low volume complex electronic. These two characteristics exposes sustainment-dominated systems to obsolescence [6,12]. In relation to this, Meyer et al. [1] highlighted that the fast changing market trends and the ongoing technical revolution in the electronics industry create a significant obsolescence management challenge for the sustainment-dominated systems.

The sustainment-dominated systems are increasingly being contracted for availability (CFA) in the defence sector. The essence of availability contracts is that the suppliers are paid for achieving an availability target for the sustainment-dominated system (typically expressed as a percentage, e.g. "available $99.50 \%$ of the time") and not just for the delivery of the product and spares/repairs [23]. This implies that before signing the contract it is necessary to estimate the whole life cost (WLC), which refers to the cost of ownership of a PSS from initial concept until eventual retirement, considering all cost categories [24], including the obsolescence cost. 
This paper aims to summarise and classify the different activities that may be included in an Obsolescence Management Plan (OMP), taking into account not only electronics but also other aspects such as mechanical components, software, materials, skills, tooling and test equipment. The paper clarifies the differences between obsolescence mitigation and resolution strategies and to classify them, identifying their strengths and weaknesses. This research is part of the "PSS-Cost" project, carried out in Cranfield University, which aims to improve the whole life cycle costing of Product-Service Systems (PSS) in the defence and aerospace sectors at the bidding stage.

The remaining part of this paper begins by explaining the obsolescence problem, the different areas of the system that can be affected by obsolescence (section 2), and the research methodology followed (section 3). Section 4 describes the most common obsolescence mitigation strategies and resolution approaches, analysing the suitability of each one. Next, the state of the art in costing and forecasting obsolescence is described and analysed (sections 5 and 6). A comparative analysis is carried out among the main commercial and noncommercial obsolescence monitoring and management tools (section 7). Finally, a set of concluding remarks and the future research challenges identified are explained in section 8 .

\section{THE OBSOLESCENCE PROBLEM}

In the defence sector, the life cycle of a project is commonly divided into six phases: concept, assessment, demonstration, manufacture, in-service, and disposal. This is represented using the CADMID cycle (Figure 1). The obsolescence issues can arise not only during the inservice phase but at any stage of the whole life cycle. Frequently, for defence systems and avionics, $70-80 \%$ of the electronic components of the system become obsolete before the system has been fielded (considering that the CADM phases may last for 15 years in long projects) $[4,5,7,10,11,20,25]$. In fact, obsolescence issues may arise even before the end of the development phase (taking into account that the CAD phases may last for more than 10 years in long projects) [12]. This suggests that obsolescence needs to be managed since early stages of the project, especially at the design stage, where several strategies to mitigate the obsolescence risk should be considered (Further details about Design for Obsolescence are provided in section 4.1.2.). 


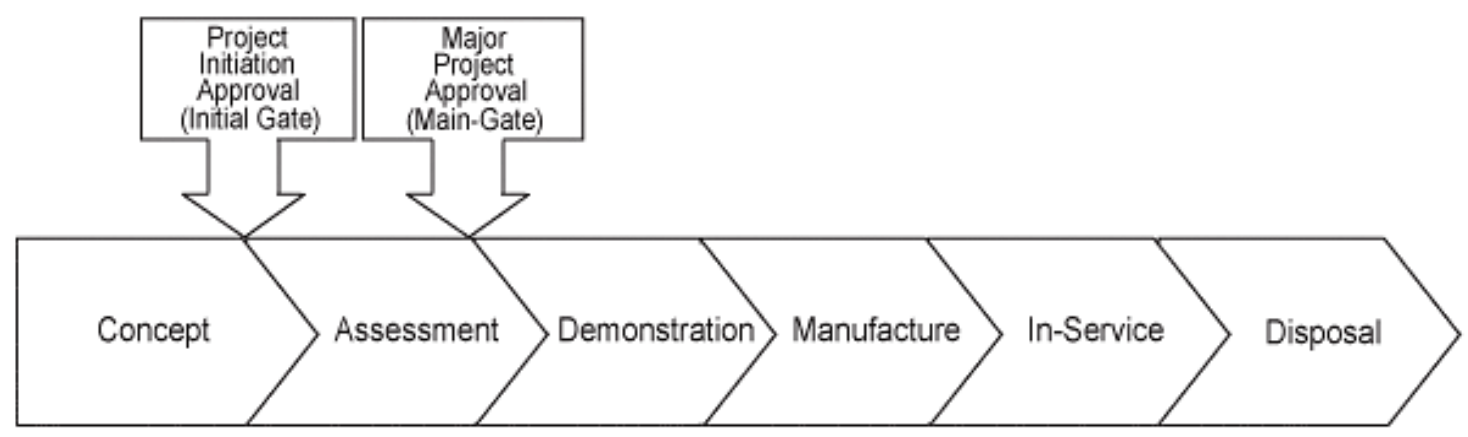

Figure 1 The CADMID Cycle

For the military, the main objective is to obtain reliable operational capability for systems at the lowest possible cost [26]. However, as the components of aging aircrafts are getting older, they are becoming more costly to maintain due to parts obsolescence or spares procurement that may extend useful life [27-29].

It is necessary to review the last 50 years of the history of the military to understand its current situation. In the $60 \mathrm{~s}$ and $70 \mathrm{~s}$, the military was able to define and control design specifications and requirements of the system, because they were developed exclusively for the military [12]. However, in the 80s the electronic components industry boomed [12], and the end of the Cold War put pressure on cutting military expenses [20]. By the early 90s, manufacturers migrated away from the low volume military market and focused their efforts on the more profitable commercial market $[11,26,30]$. The consequence is that from the $80 \mathrm{~s}$ onwards, technology obsolescence has become a major issue for the military and the aerospace industry $[11,18,31]$.

\subsection{HOLISTIC VIEW OF OBSOLESCENCE}

DMSMS (Diminishing Manufacturing Sources and Materials Shortages) is the term used by the American defence industry to refer to electronic part obsolescence (and technology obsolescence in a general manner) $[17,20]$. Many authors $[3,6,7,32-34]$ agree that electronic parts are becoming obsolete at a fast pace due to the rapid growth of the electronics industry and the potential impact on readiness and supportability are more immediate. The problem of the obsolescence of components is mainly related to electronic parts, but it is not restricted to them. There are many other areas of a sustainment-dominated system that can become obsolete such as: (Figure 2) 




Figure 2 The Holistic View of Obsolescence

\section{Mechanical Components and Materials}

Mechanical parts in aging systems break down frequently and in unexpected ways [7]. Failures of these parts can trigger obsolescence when the system reaches the aging phase due to the potential unavailability of spares and materials. As suppliers develop stronger, lighter, and more damage resistant materials, older materials become obsolete and phase out for new production [7]. The new materials may be better in many respects, but do not always have the right mechanical or chemical properties to be a direct replacement for an older material. The lack of a direct replacement may drive a component redesign, and consequently it will have an impact on the Whole Life Cycle Cost (WLCC) of the system. Materials often become obsolete due to new environmental regulations such as the Restriction of Hazardous Substances Directive (RoHS) [35]. Moreover, it is common that during the in-service phase the materials are only required in small quantities. This clashes with the high Minimum Order Quantities (MOQ) imposed by many suppliers, hindering their sourcing and triggering obsolescence issues.

\section{Processes and Procedures}

Changes in the environmental regulations are the most common drivers of obsolescence in manufacturing processes [7]. In the light of this, a material obsolescence issue can make a manufacturing process obsolete and also the obsolescence of a manufacturing process can 
prevent the manufacture of a material (with a particular set of specifications) making it obsolete. Therefore, these two areas are usually interrelated.

\section{$>$ Software and Media}

In most complex systems, as Sandborn [36] stated, "software life cycle costs (redesign, rehosting and re-qualification) contribute as much or more to the total life cycle cost as the hardware, and the hardware and software must be concurrently sustained". Although software obsolescence is one important aspect that should be considered to estimate the whole life cycle costs (WLCC) of a system, little attention has been paid to this area so far. Indeed very few organisations in the defence industry are managing and costing software obsolescence properly [36, 37,38].

The technology used for storing data, software and documents is continuously changing. The fact that new technologies bring benefits (e.g. higher storage capacity, lower physical space, and higher data-transmission speed) and in general are not compatible with older technologies implies that periodically the media and formats need to be upgraded.

\section{$>$ Skills and knowledge}

The skills and knowledge available within the organisation need to be managed wisely in order to avoid losing them if they may be required for the sustainment of long-life systems. This is the only type of obsolescence that can be completely mitigated by deploying appropriate obsolescence management strategies such as: keeping a "skill register" database, identifying potential skill shortages and tackling them with training schemes, outsourcing, using standarisation (preferred technology) to minimise the number of programming tools used across the organisation. If the skills obsolescence is not tackled, it can drive obsolescence issues in other areas such as software.

\section{Manufacturing tooling}

The manufacturing aides required to fabricate the components is regarded as 'tooling' (e.g. forging dies, holding fixtures, sheet metal patterns, casting molds) [7]. Obsolete tooling may need to be refurbished or recreated. Otherwise, it may impact on the manufacturing process. Likewise, a change in the manufacturing process driven by a change in material or form may cause the tooling to become obsolete.

\section{Test equipment}

The test equipment becomes obsolete at the end of the production phase because it is no longer required [7]. However it may be necessary to test if a replacement for a component is form, fit, function, and interface compliant to tackle a component obsolescence issue. 
At the moment, few authors [7,37,39-41] have studied in-depth the obsolescence problem outside the electronics area. However, the obsolescence impact in each of these areas should not be underestimated.

\section{RESEARCH METHODOLOGY}

A comprehensive investigation has been carried out in order to identify any publications related to the area of 'obsolescence'. For this purpose the main keywords used were: 'obsolescence', 'obsolete' and 'DMSMS' (Diminishing Manufacturing Sources and Material Shortages - this acronym is used in the U.S. to refer to obsolescence). The results were refined using keywords such as 'component', 'system', 'part', 'material', 'hardware', 'software', 'assembly' and 'LRU' ("Line-replaceable unit”). A number of databases were explored, including EBSCO, SCOPUS, CSA, SCIRUS, STINET, Science Direct, ProQuest, IEEE Xplore and Emerald. On top of that, searching tools such as 'Engineering Village' and 'ISI Web of Knowledge' were used. The search was narrowed down to the military and aerospace sectors using keywords such as 'military', 'defence', 'aerospace' and 'avionics'. The title and abstract of all the papers retrieved were manually explored and analysed to ensure that they are suitable for this survey.

This investigation concludes that research on the 'obsolecence' topic commenced within the last 20 years and the trend has been increasing since then as shown in Figure 3. This graph is based on the 325 hits retrieved following the procedure explained above and limited to the period between 1996 and 2009, considering that the number of publications on this topic before 1996 can be regarded as insignificant. 


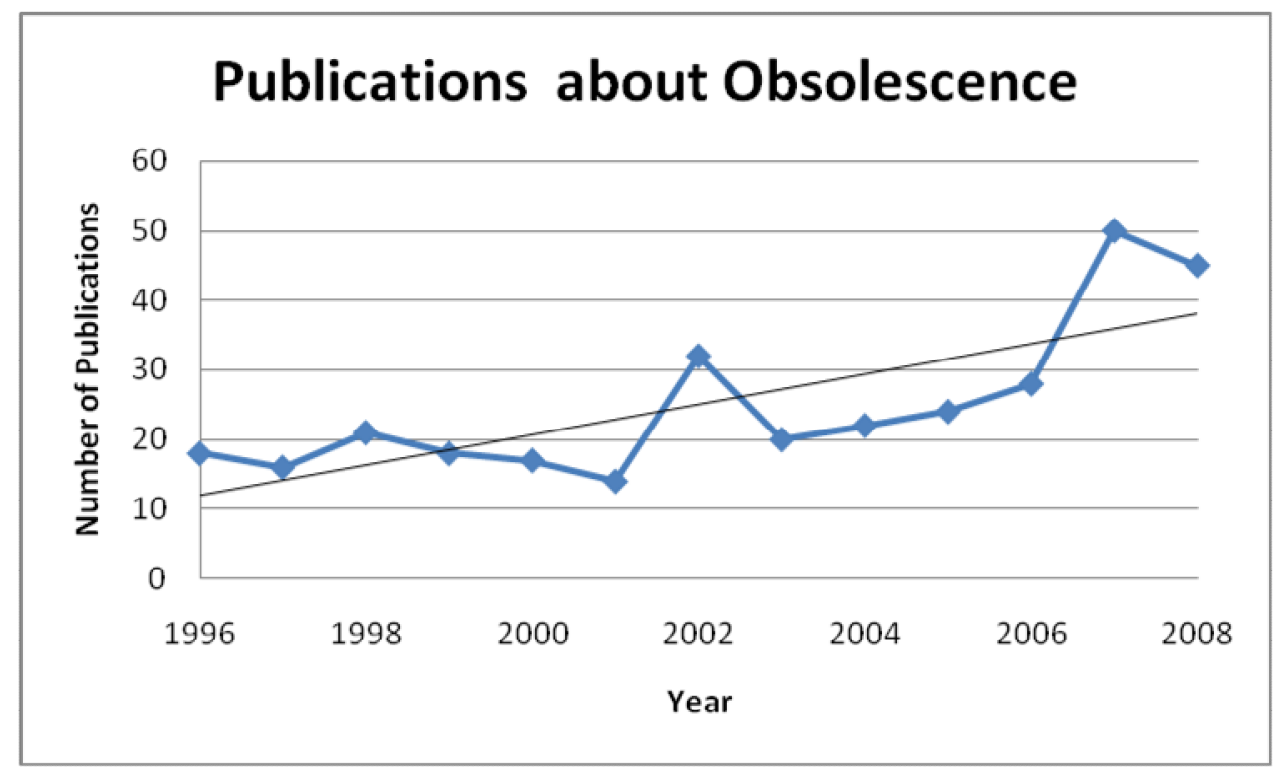

Figure 3 Yearly Publications on Obsolescence within the Defence \& Aerospace Sector

The most relevant papers were read and analysed further. This allowed the identification of trends and key areas that were covered by many papers. Those areas are namely 'mitigation \& resolution approaches', 'design for obsolescence', 'obsolescence costing', 'obsolescence management tools', 'COTS' (Commercial off-the-shelf), 'software obsolescence', 'electronics obsolescence', 'mechanicals obsolescence', 'component level', 'assembly level', 'system level', and represent the research scope within the 'obsolescence' topic. The papers were classified according to those categories as illustrated in Table $\mathbf{1 .}$ 
Table 1 Classification of key papers on 'obsolescence'

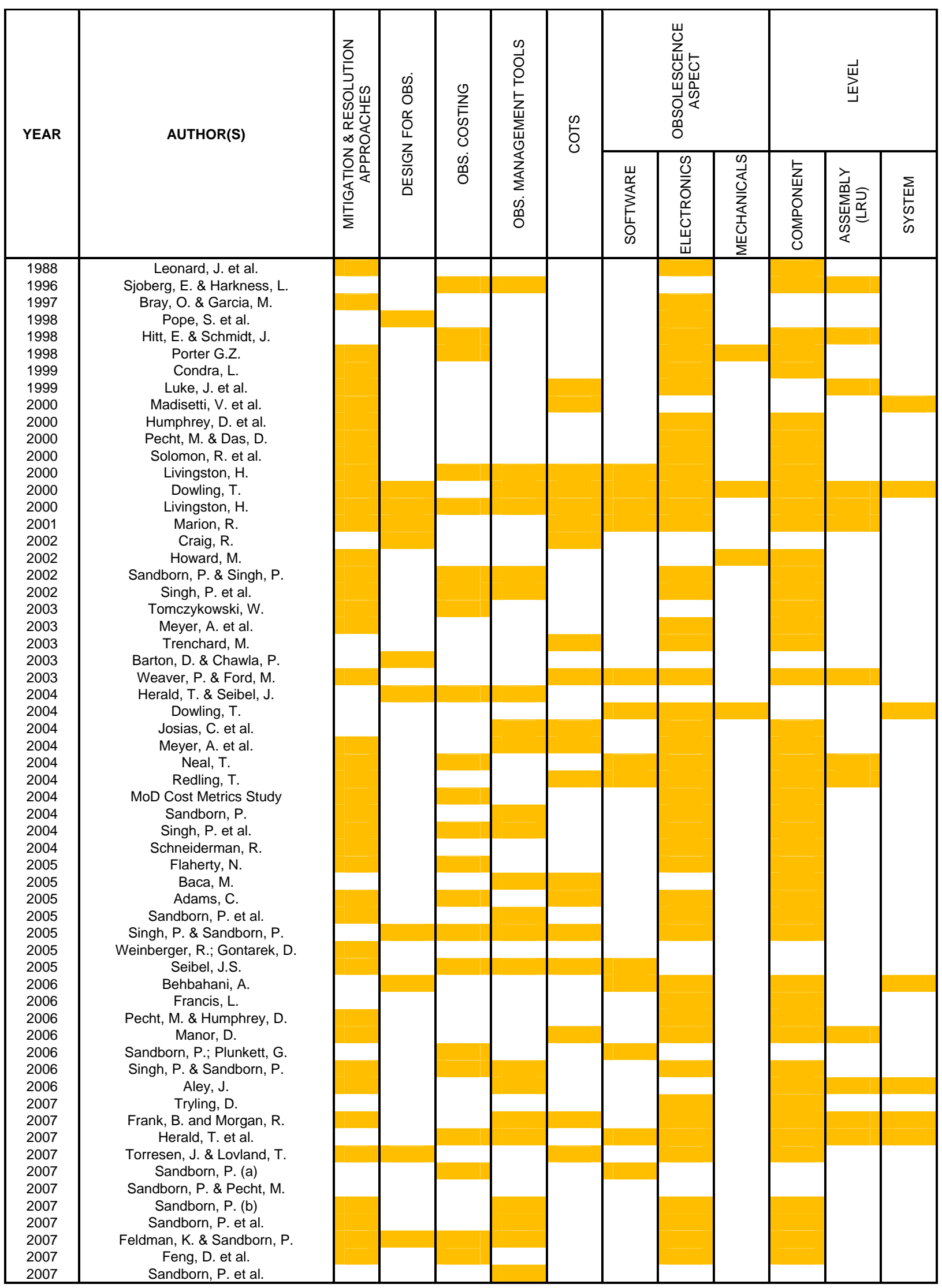


This classification shows that most of the research on obsolescence has been focused on the electronic components, whereas not many papers have considered the obsolescence in other aspects of the system such as software or mechanicals. It can also be appreciated from this classification that most of the papers have dealt with obsolescence at the component level and neither at the assembly nor system level. This is justified by the fact that the electronic components are the part of the system that more frequently suffer the effects of obsolescence. Another fact that can be appreciated from this classification is that there are many papers where the obsolescence resolution and mitigation approaches are explored but just a few highlight the "design for obsolescence" as a key mitigation strategy. The classification also shows that there is no clear trend towards a particular area within the obsolescence topic in recent years.

\section{OBSOLESCENCE MITIGATION AND RESOLUTION}

Until recently, managers and designers were unaware of how to manage obsolescence, so they tended to deal with it in a reactive mode, searching for 'quick-fix' solutions to resolve the obsolescence problem once it has appeared [1,7]. Several authors $[1,2,12,18]$ advised earnestly to apply obsolescence mitigation approaches in a proactive manner and involving all the projects related, in order to minimise the obsolescence problem. In 2007, Herald et al. [41] demonstrated with their research that by improving the obsolescence management, the costs related can be considerably reduced. Figure 4 shows how the evolution of the obsolescence level differs from implementing a proactive versus a reactive approach. 


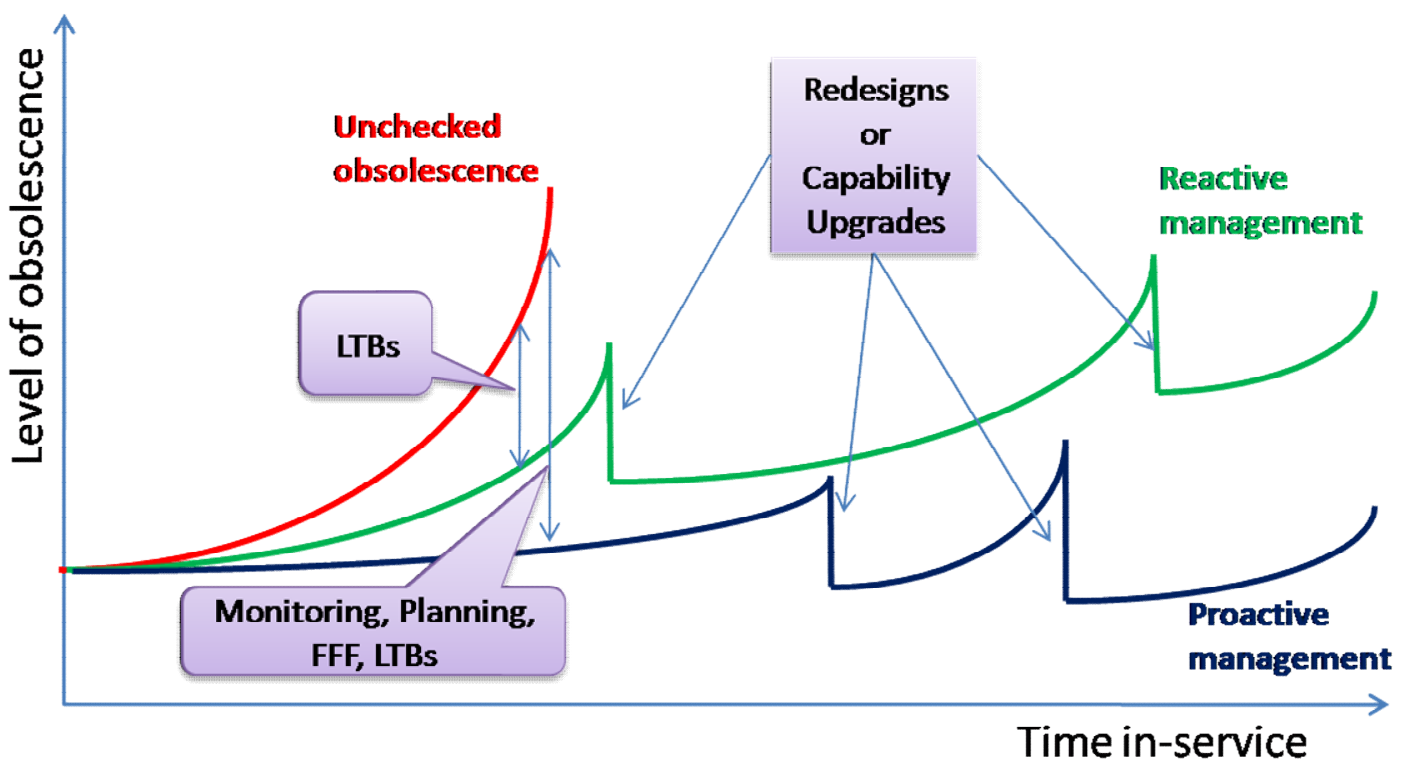

Key: FFF-Form, Fit and Function Replacement; LTBs-Last Time Buys

Figure 4 Evolution of the Level of Obsolescence Based on the Management Approach

Traditionally, the military has dealt with obsolescence in a reactive mode [12]. However, this approach is inadvisable because finding a solution with little advance warning is expensive $[12,33,42]$. Several authors $[1,7,12,13,18,27,33,43-46]$ have highlighted the need to change from reactive to proactive approaches concerning obsolescence. However, it is necessary to emphasise that the level of 'proactiveness' that should be put in place depends on an initial assessment, at the component level, of the probability for a component to become obsolete and the impact that it would have on costs (Figure 5). If the obsolescence of the component has low impact on costs (e.g. because a form, fit and function (FFF) replacement is easy to be found), it may be worthwhile to decide to deal with that component in a reactive mode. Note that this decision is taken after performing the risk assessment, so this is part of a proactive obsolescence management. If the probability of becoming obsolete is low but it may have a high impact on costs, it is necessary to put in place proactive mitigation measures. If both the probability of becoming obsolete and the impact on costs are high, this component is regarded as 'critical' and hence it is necessary to emphasise the proactive mitigation strategy on it. 


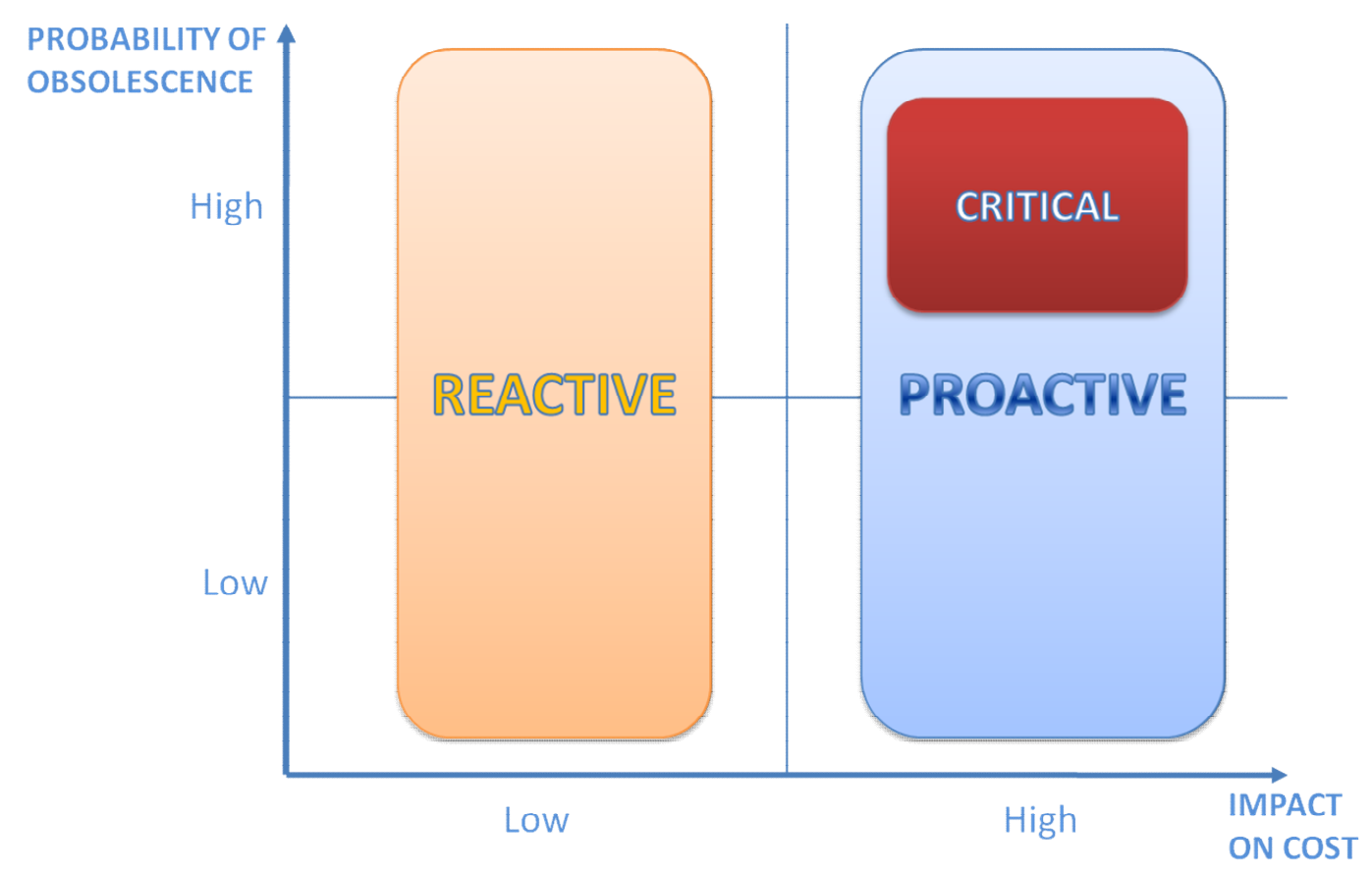

Figure 5 Levels of 'Proactiveness' in Obsolescence Management

In the literature the terms 'mitigation' and 'resolution' are frequently used interchangeably. However, the authors consider that it is important to make a distinction between their meanings. The term 'mitigation' refers to the measures taken to minimise the impact or likelihood of having an obsolescence problem, whereas the term 'resolution' refers to the measures taken to tackle an obsolescence issue once it appears. The most common resolution approaches and mitigation strategies are described as follows.

\subsection{OBSOLESCENCE MITIGATION MEASURES}

The strategy followed in the obsolescence management is usually a combination of mitigation measures. Obsolescence risk can be mitigated by taking actions in three main areas: supply chain, design and planning as shown in Figure 6. 


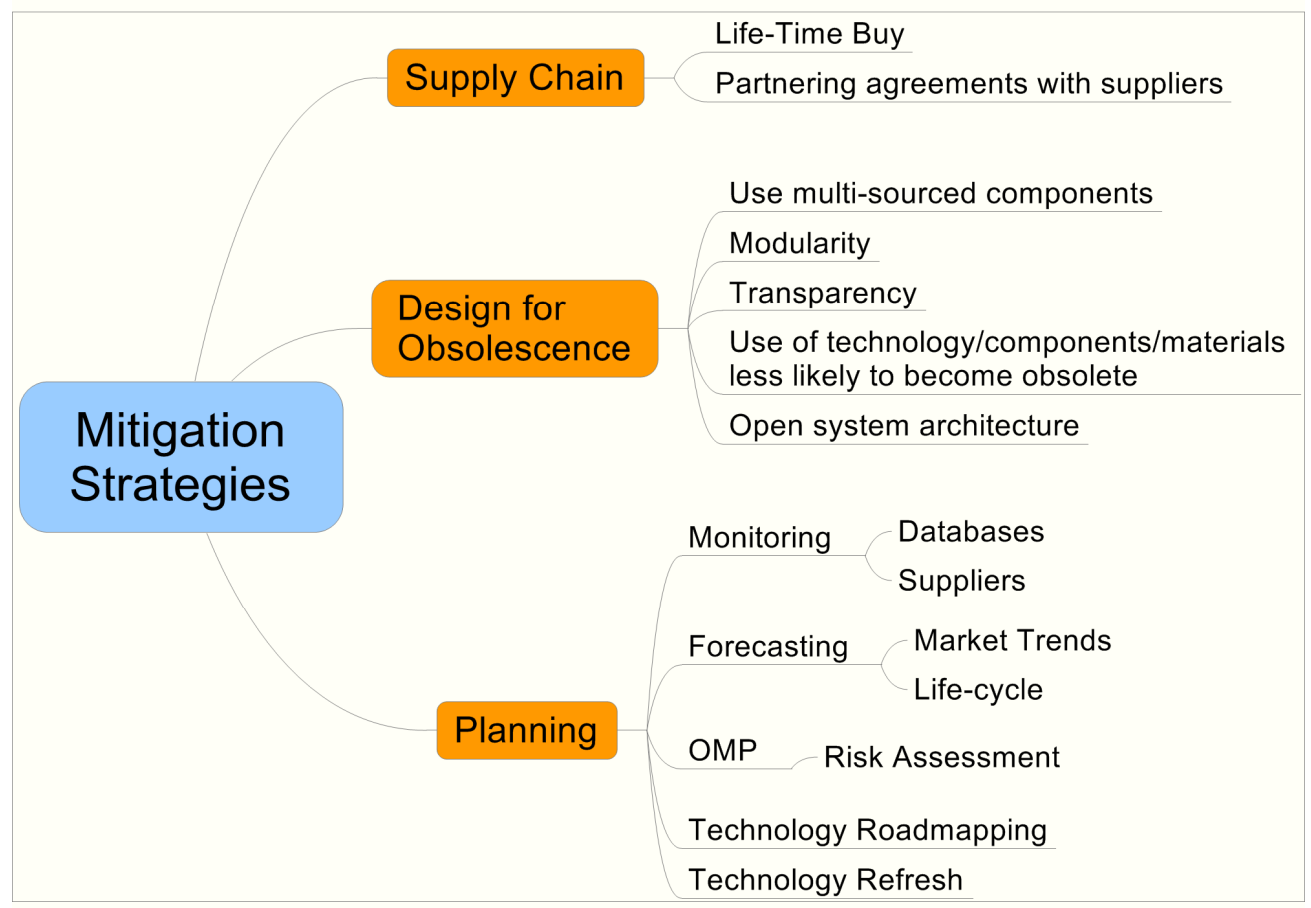

Figure 6 Obsolescence Mitigation Strategies

\subsubsection{Supply Chain}

The mitigation measures that can be taken in the supply chain are: Life-time Buy (LTB) and partnering agreements with suppliers.

- Life-time Buy (Life of Type)

The Life-time Buy (LTB) or Life-of-Type (LOT) approach involves purchasing and storing enough obsolete items to meet the system's forecasted lifetime requirements $[2,5,33]$. Feng et al. [14] addressed the optimisation of the process to determine the number of parts required for the life-time buy to minimise lifecycle cost. The key cost factors identified are: procurement, inventory, disposal and penalty costs [14].

The main benefit of this approach is that readiness issues are alleviated [47] and it avoids requalification testing. However, several drawbacks have been identified:

Initial high cost, incurring in significant expenses in order to enlarge the stock $[14,47]$.

It is difficult to forecast the demand and determine life-time buy quantity accurately [14]. Therefore, it is common to have excess or shortage of stock problems.

This approach assumes that the system design will remain static [14]. Any unplanned design refresh may make stock obsolete and hence no longer required. 
$>$ The customer is in a poor negotiation position because of the high dependence on a particular supplier [16].

\section{- Partnering Agreements with Suppliers}

Nowadays, the defence industry has less control over the supply chain for COTS electronic components $[4,13,14]$. This type of components is becoming obsolete at an increasingly fast pace. Therefore, it is advisable to make partnering agreements with suppliers to ensure the continuous support and provision of critical components.

\subsubsection{Design for Obsolescence}

The fact that military systems will be affected by technology obsolescence during their lifetime is unavoidable $[4,48]$. Therefore, several authors $[1,4,26,27]$ suggested trying to address this threat at the design stage. Feldman and Sandborn [6] pinpointed that "managing obsolescence via quickly turning over the product design is impractical because the product design is fixed for long periods of time", highlighting the importance of doing it at the beginning of the project. Therefore, strategies such as the use of open system architecture, modularity and increase of standardisation in the designs will definitely ease the resolution of obsolescence issues that may arise at the component or line replaceable unit (LRU) level $[25,29,39]$.

Condra [13] argued that the impact of electronic components obsolescence on the life cycle cost and functionality of a military aircraft can be drastically reduced considering the following guidelines:

$>$ Managing the processes used to select and manage components to assure costeffectiveness, reliability, safety, and functionality.

$>$ Developing new approaches to using components manufactured for other industries (incorporating Commercial off-the-shelf (COTS)) [49].

Therefore, according to Condra [13], the military should get ready to make use of electronic components designed for the commercial market. However, the incorporation of COTS in the system is a double-edged sword due to their shorter life-cycle. The authors argue that this decision may increase the frequency of obsolescence issues in the system, exacerbating the problem.

- Use Multi-sourced Components

At the design stage it is important to take into account the number of suppliers and manufacturers that are producing a particular component (implementing a particular 
technology) before including that component in the Bill of Materials (BoM). It is necessary to make sure that the components included in the BoM can be provided by multiple suppliers to minimise the number of critical components.

\subsubsection{Planning}

Planning is an effective way of mitigating obsolescence. It implies the development of an Obsolescence Management Plan (OMP), a technology roadmap and the use of obsolescence monitoring tools.

\section{- Technology Roadmapping}

The use of Technology Roadmapping facilitates the selection of technologies to go ahead with, while considering timeframes. It enables the identification, evaluation, and selection of different technology alternatives [50]. Furthermore, it identifies technology gaps, which can be regarded as the main benefit of this approach because it helps to make better technology investment decisions [50]. The use of this technique may help to plan the technology refreshes that the system may require within the 'In-Service' phase of the CADMID cycle, solving and preventing obsolescence issues.

\section{- Monitoring}

Nowadays, there are many commercial tools available that enable the monitoring of the BoM. In general they match the BoM with huge databases, providing information about the current state of each component (whether it is already obsolete or not) and a forecast about when it will become obsolete. The forecasting is based on an algorithm that takes into account several factors such as type of component and technology maturity. These algorithms are currently been improved to take into account other factors such as market trends. The monitoring tools may provide information about FFF alternatives to replace obsolete components. All this information provides the basis for the planning and proactive management of obsolescence.

\section{- Obsolescence Management Plan (OMP)}

It has become a common practice for the Original Equipment Manufacturer (OEM) to produce a document called the Obsolescence Management Plan (OMP) to satisfy the MoD demand. The OMP describes the proactive approach to be taken by the OEM to manage, mitigate and resolve obsolescence issues across the life-cycle of the PSS [51]. This document provides the OEM and the customer with a common understanding of the obsolescence risk and allows the agreement of the most suitable obsolescence management strategy. 


\subsection{OBSOLESCENCE RESOLUTION APPROACHES}

When a part becomes obsolete, a resolution approach must be applied immediately to tackle the problem $[2,10,47]$. It is important to make sure that no pre-existing capabilities are lost with the resolution approach selected [26]. There are several resolution approaches in the literature which are described as follows, but the suitability of them depends on the individual case $[9,48]$. The different approaches are classified according to the replacement used into four categories. (Figure 7)

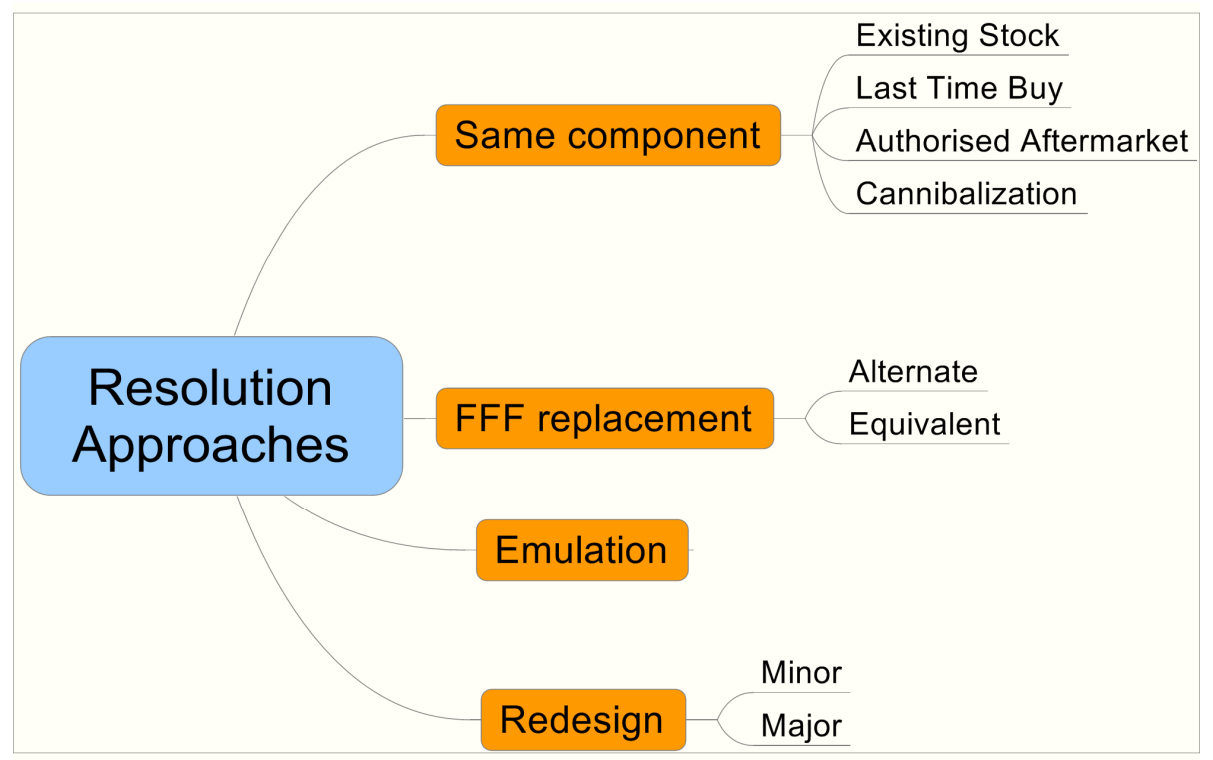

Figure 7 Obsolescence Resolution Approaches

\subsubsection{Same Component}

- Existing Stock

It is stock of the obsolete part available within the supply chain that can be allocated to the system. This is the first resolution approach that should be explored because it is inexpensive, but it is just a short-term solution. Therefore, a long-term solution should be implemented afterwards.

- Last-time Buy

The Last-time Buy (LTB) is the purchase and store of a supply of components, as a result of a product discontinuance notice from a supplier, sufficient to support the product throughout its life cycle or until the next planned technology refresh (Bridge Buy) $[1,5,6,18,33]$. This resolution approach differs from the Life-time Buy in the fact that the Last-time Buy is triggered by a supplier announcing a future end of production whereas the Life-time Buy is a risk mitigation option triggered by the user's risk analysis. 
The main advantage of this approach is that it allows extending the time since the Product Change Notification (PCN) is received until performing a redesign [18,47]. This is a common and effective approach, but in general it is used as a short-term solution until a more permanent solution can be placed $[7,16,18,47]$.

- Authorised Aftermarket Sources

Occasionally the obsolete part can be procured from third parties authorised by the Original Equipment Manufacturer (OEM), once the OEM has stop producing it $[2,5,33]$. This is a beneficial solution because it is relatively inexpensive $[47,52]$.

\section{- Reclamation (Cannibalization)}

The Reclamation approach, also known as Cannibalization, consists in using serviceable parts salvaged from other unserviceable systems $[1,2,5]$. This approach is especially useful during the last stage of the in-service phase in legacy systems, but the used part may be just as problem-prone as the one it is replacing [16].

- Other Approaches: Grey Market and Secondary Market

The grey market is the trade of new goods through distribution channels which are unauthorised, unofficial, or unintended by the original manufacturer. Some companies rely on the grey market as an alternative to performing a redesign. However, this is very risky due to the increasing probability of purchasing counterfeit components when using these sources [53]; especially in sectors such as the defence and aerospace, where counterfeit components can compromise the safety of people. Besides, testing of all the components to ensure that they are not a counterfeit is usually not feasible. Therefore, this is an inadvisable approach. It is tempting to buy obsolete components in the secondary market using internet tools such as eBay. However, several authors $[16,47]$ agree that "this is a chancy solution because the used part may be just as problem-prone as the one it is replacing”. Furthermore, this approach is as prone to counterfeits as the grey market.

\subsubsection{Form Fit Function Replacement (FFF)}

There are two types of FFF replacement:

- Equivalent

An equivalent is a functionally, parametrically and technically interchangeable replacement, without any additional changes $[2,5,33,47,52]$. The main benefit of this approach is that it is inexpensive (as requalification tests are not required) and frequently a long-term alternative 
$[7,26,47]$. However, it is difficult to find a replacement with the same form, fit and function [52].

\section{- Alternate}

An equivalent can be defined as "a part available whose performance may be less capable than that specified for one or more reasons (e.g., quality or reliability level, tolerance, parametric, temperature range)" [54]. Equivalent items may perform fully (in terms of form, fit, and function) in place of the obsolete item but testing is required. Uprating is the process of assessing the capability of a commercial part to meet the performance and functionality requirements of the applications, taking into account that the part is working outside the manufacturers' specification range $[2,5,30,55]$.

\subsubsection{Emulation}

The emulation approach consists in developing parts (or software) with identical form, fit and function than the obsolete ones that will be replaced, using state of the art technologies $[2,5,33]$. The emulator can be an interface software that allows continuing the use of legacy software in new hardware where otherwise the legacy software would not work properly. The fact that this solution is frequently based on COTS components with a build-in adapter [45] can turn it into a short-term solution.

\subsubsection{Redesign}

The Redesign alternative involves making a new design for obsolete parts by means of upgrading the system, with the aims of improving its performance, maintainability and reliability, as well as enabling the use of newer components [5,33]. Several authors $[7,14,20]$ agree that this is the most expensive alternative (especially for the military, taking into account the re-qualification/re-certification requirements). Therefore, this long-term solution should be used as a last resort and when functionality upgrades (technology insertion) become necessary.

\section{OBSOLESCENCE COSTING}

Traditionally, contracting for a "sustainment-dominated systems" did not include the cost of resolving obsolescence issues. The OEM used to be in charge of solving those problems and the customer used to pay for it separately. However, the current contracting trend is moving towards contracting for availability (CFA). This type of contracts, in theory, is diverting the obsolescence risks from the customer to the OEM. In practice, the risk of obsolescence is 
shared between both parties in accordance with the clauses agreed in the contract [23]. On the whole, this new way of contracting brings both parties to a new scenario in which they need to make accurate estimations of the obsolescence cost at the bidding stage. Both the OEM and the customer need to be confident that the cost estimates for the WLC are correct because of the long periods contracted for and the little profit margin of the OEM. Therefore, the cost estimations need to be reliable. In order to estimate the cost it is necessary to identify the cost drivers [56]. It is identified the need for a cost model to estimate the total cost that will be incurred mitigating and solving obsolescence issues. It should be capable of estimating the obsolescence cost even when information such as the BoM, the obsolescence predictions of a monitoring tool and the obsolescence management plan (OMP) are not in place yet. However, this tool should be just intended to assist in estimating the cost, considering that simple mathematical models cannot replace the expert judgment of the cost estimator [1]. There are many commercial tools, such as TruePlanning [57] and SEER [58], designed to estimate the life cycle costs of systems. However, none of these tools is focused on accurately estimating obsolescence costs.

A major challenge for the estimation of costs related to obsolescence is the development of accurate cost metrics. The cost metrics allow the: selection of the most cost effective solution, cost avoidance analysis and assessment of the impact of obsolescence on whole life cycle costs [54]. In 1999, the Department of Defence (DoD) in the United States was concerned about this, so they commissioned the Defense MicroElectronics Activity (DMEA) to develop cost factors for various obsolescence solutions. In 2001, the DoD commissioned a supplementary report but no significant data was received to justify changing the 1999 values. Due to differences in practices, cost and terminology between the US and UK, in 2004, the Ministry of Defence (MoD) in the UK commissioned QinetiQ and ARINC to derive a set of cost metrics that may be used for the estimation of costs related to obsolescence (See Figure 8). However, those cost metrics have been subjected to criticism and the MoD is aware that they need to be revalidated. 




Figure 8 UK versus DMEA Resolution Cost Metrics (Adopted from [54])

The costs estimated for each mitigation alternative should be compared with the cost of maintaining the obsolete system and with the cost of redesigning it [11]. On the one hand, it is advised to "keep the old equipment until the cost of replacing it is less than the cost of maintaining it" [27]. On the other hand, it may be sensible to assess the redesign cost, taking into account that it is divided into the development and acquisition costs, and component requalification costs [48].

\section{OBSOLESCENCE FORECASTING}

According to what has been discussed so far, it is clear that obsolescence is a problem that should be tackled in a proactive manner. For this purpose, it is necessary to foresee when those obsolescence issues will appear. The following factors should be taken into account:

$>$ Type of component (e.g. electronic or mechanical)

$>$ Complexity of the component (e.g. low complexity such as resistors or high complexity such as microprocessors or LCD displays)

$>$ Technology built in the component

$>$ Level of maturity of the technology built in the component

$>$ Number of suppliers of the component 
$>$ Market trends

$>$ Changes in laws and regulations

Nowadays, most of the commercial monitoring tools [59] (such as Q-Star, IHS, TACTRAC) incorporate an algorithm to forecast obsolescence dates based on the features of the component and the technology that it incorporates, making use of life cycle models. Besides, those algorithms are continuously been refined and it is expected that in the near future they may be capable to take into account other factors such as market trends.

For the development of an algorithm capable of forecasting technology obsolescence, it is necessary to make use of a detailed database, containing historical data about last-order or last-ship dates and information about the system components $[6,43,48]$. However, much of this data is highly uncertain. Therefore, it is important to manage the following two types of uncertainties: [2]

Uncertainty in the cost analysis inputs

$>$ Uncertainty in dates

Although the data about the expected production lifetimes of parts available during a system's design phase may be incomplete and/or uncertain, it will allow the forecast of obsolescence and subsequent development of strategic approaches that will reduce sustainment costs $[4,22]$. Sandborn et al. [43] expressed concern about the importance of the data at the system's design stage and developed data mining based algorithms that allow finding out more information, increasing the predictive capabilities. Frequently, the obsolescence forecasting is used not only for planning design refresh but also in order to avoid the inclusion of parts with high risk of imminent obsolescence in the BOM at the design stage [4].

Various authors [1,43] advised the use of obsolescence monitoring in order to obtain timely notification of any obsolescence risk. Nowadays, most of the organisations that are trying to manage obsolescence proactively are implementing commercial tools that allow the monitoring of the state of the components included in the BoM of any system. It provides information of possible FFF replacements for some obsolete items or even before the obsolescence problem arises. In the next section, the main obsolescence management tools are compared. 


\section{OBSOLESCENCE MANAGEMENT TOOLS COMPARISON}

The main commercial and non-commercial tools available at present have been analysed and compared (based on publicly available information) according to their features in the following table.

Table 2 Comparison of the main obsolescence management tools

\begin{tabular}{|c|c|c|c|c|c|c|}
\hline $\begin{array}{c}\text { OBSOLESCENCE } \\
\text { TOOLS }\end{array}$ & Forecasting & $\begin{array}{c}\text { Monitoring \& } \\
\text { Identification } \\
\text { of Alternative } \\
\text { Components } \\
\end{array}$ & $\begin{array}{l}\text { Mitigation } \\
\text { Strategy } \\
\text { Development }\end{array}$ & Costing & Level & $\begin{array}{c}\text { Types of } \\
\text { Obsolescence }\end{array}$ \\
\hline Q-Star & $\checkmark$ & $\checkmark$ & & & $\mathrm{C}$ & oElectronics \\
\hline ITOM & $\checkmark$ & $\checkmark$ & & & $\mathrm{C}$ & $\begin{array}{l}\text { oElectronics } \\
\text { o Electromechanical }\end{array}$ \\
\hline $\begin{array}{l}\text { Obsolescence } \\
\text { Manager }\end{array}$ & $\checkmark$ & $\checkmark$ & & & $\mathrm{C}$ & $\begin{array}{l}\text { oElectronics } \\
\text { ○Electromechanical }\end{array}$ \\
\hline $\begin{array}{l}\text { i2 TACTRAC + } \\
\text { i2 Electronics } \\
\text { Database }\end{array}$ & $\checkmark$ & $\checkmark$ & & & $\mathrm{C}$ & $\begin{array}{l}\text { o Electronics } \\
\text { o Electromechanical }\end{array}$ \\
\hline Parts Plus & $\checkmark$ & $\checkmark$ & & & $\mathrm{C}$ & ○Electronics \\
\hline AVCOM & $\checkmark$ & $\checkmark$ & $\begin{array}{l}\text { The MTI group } \\
\text { can define it at } \\
\text { the component } \\
\text { level }\end{array}$ & & $\mathrm{C}$ & $\begin{array}{l}\text { ○ Electronics } \\
\text { ○ Non-electronics }\end{array}$ \\
\hline OASIS & & $\checkmark$ & & & $\mathrm{C}$ & oElectronics \\
\hline MOCA tool & $\checkmark$ & & $\checkmark$ & $\checkmark$ & A & ○Electronics \\
\hline Se-Fly Fisher & $\checkmark$ & & $\checkmark$ & & S & $\begin{array}{l}\text { oElectronics } \\
\text { o Electrical } \\
\text { o Mechanical } \\
\text { o Software }\end{array}$ \\
\hline R2T2 & $\checkmark$ & $\checkmark$ & $\checkmark$ & $\checkmark$ & $S$ & $\begin{array}{l}\text { ○ Hardware Systems } \\
\text { o Software Systems } \\
\text { o Information } \\
\text { Technology } \\
\text { systems }\end{array}$ \\
\hline $\begin{array}{l}\text { CAPSXpert / } \\
\text { CAPS BOM } \\
\text { Manager }\end{array}$ & & $\checkmark$ & & & $\mathrm{C}$ & $\begin{array}{l}\text { ○ Electronics } \\
\text { } \text { Electromechanical }\end{array}$ \\
\hline CAPS Forecast & $\checkmark$ & & & & $\mathrm{C}$ & $\begin{array}{l}\text { o Electronics } \\
\text { oElectromechanical }\end{array}$ \\
\hline \multicolumn{7}{|c|}{$\begin{array}{l}\mathrm{C} \rightarrow \text { Component Level } \\
\mathrm{A} \rightarrow \text { Assembly Level } \\
\mathrm{S} \rightarrow \text { System Level }\end{array}$} \\
\hline
\end{tabular}

Table 2 illustrates that most of the tools are focused on the monitoring of the BoM and identification of alternative components for the obsolete ones. Furthermore, most of them are focused on electronic and electromechanical components, as they are more prone to obsolescence due to the ongoing change in technology. 
The models have been classified into three categories as shown in Table 2 [60]:

$>$ "Component Level" represents the models that forecast the next obsolescence event for each independent electronic component.

> "Assembly Level" represents the tools that manage an assembly (LRU), which is composed of components, determining the optimal time to change its baseline during production and operation due to part-level obsolescence.

"System Level" represents those models that address the obsolescence for the entire system, taking into account different aspects such as hardware and software integration. Those models are able to forecast obsolescence at the system level, across the remaining life cycle and optimise the change frequency [60]. The data inputs required for this type of model are not usually available in most databases.

Singh and Sandborn [22] identified two different types of strategic planning approach:

Material Risk Index (MRI)

This approach analyzes the BoM of a product and grades for each component the likelihood of becoming obsolete [4,22].

$>$ Design Refresh Planning

This method determines the optimum design refresh plan during the field-support-life of the product [61]. According to Sandborn and Singh [61], the design refresh plan minimises the life cycle sustainment cost of the product, defining the number of design refresh activities, their content and when they will be performed.

Some companies have developed a range of tools so that the customers can select the one that best suits their necessities. For instance, Total Parts Plus Inc. [62] offers a basic tool "Parts Xpert"M" and a superior tool "Parts Plus ${ }^{\mathrm{TM} " ; ~ i n ~ a ~ s i m i l a r ~ m a n n e r ~ " Q-S t a r " T M ", ~ " I T O M " ~}$ "Obsolescence ManagerTM" belong to QinetiQ Ltd. [63]; "OASISTM" and "AVCOMTM" belong to MTI Inc. [64,65]; "CAPSXpert"TM", "CAPS BOM ManagerTM" and "CAPS Forecast ${ }^{\mathrm{TM}}$ " belong to PartMiner Inc. [66].

Herald et al. [41,67] have developed "Se-Fly Fisher" and the "Rapid Response Technology Trade" Study (R2T2 $\left.{ }^{\mathrm{TM}}\right)$, which is the only tool that manages obsolescence at the system level. PartMiner's Life Cycle Forecast data is derived using mathematical algorithms developed in conjunction with Sandborn and the University of Maryland. 
Singh, Sandborn and Feldman, from the University of Maryland, have designed a software tool that enables the prediction of the optimum design refresh plan (MOCA tool) $[2,4,6,10,17,20,22,43,61,68]$. This tool simultaneously optimises multiple redesigns and multiple obsolescence mitigation approaches, based on forecasted electronic part obsolescence $[2,4,6,10]$.

In addition to the foregoing approaches, other obsolescence forecasting methods can be found in the literature:

$>$ The simplest model was developed by Porter [69]. This method formulates refreshes as a function of the time, based on the Net Present Value (NPV) of last-time buys. A trade-off between design refresh costs and last-time buy costs is performed on a part-by-part basis [69].

$>$ The "scorecard" approach has been traditionally used for life-cycle forecasting. Based on a set of technological attributes, the current life-cycle stage of a component can be determined [5]. However, this method has certain drawbacks: [5]

- The market trends are not accurately captured

- It makes erroneous assumptions about the life-cycle curve

○ In the forecasting it is not shown a measure of confidence

The "Availability Factor" method. This method is used to predict the obsolescence of products with similar technology and market characteristics, based on market and technology factors [5]. However, this method has certain drawbacks:

- This approach does not use the "life cycle curve" for the product.

- It is not suitable to determine the life cycle stage of the part.

Solomon et al. [5] developed an approach able to predict the years to obsolescence and life cycle stage based on modelling the life cycle curve considering the characteristic of the parts and its technology. This methodology is composed of seven steps which are described in Figure 9.

$>$ In 2004, Josias et al. [12] developed a multiple regression model for forecasting obsolescence, applied to microprocessor for computers.

The "se-Fly Fisher" is a technology-based obsolescence model developed by Herald et al. [41], based on the technology curves of each part of the system. The main outputs are: 
○ A forecast about how often a system baseline should synchronously change in order to minimise the system ownership costs through support.

- A resource identification, technical change management and assessment of scope impacts of the recommended changes.

- An assessment of the performance potential that is gained from each proposed system element baseline change.

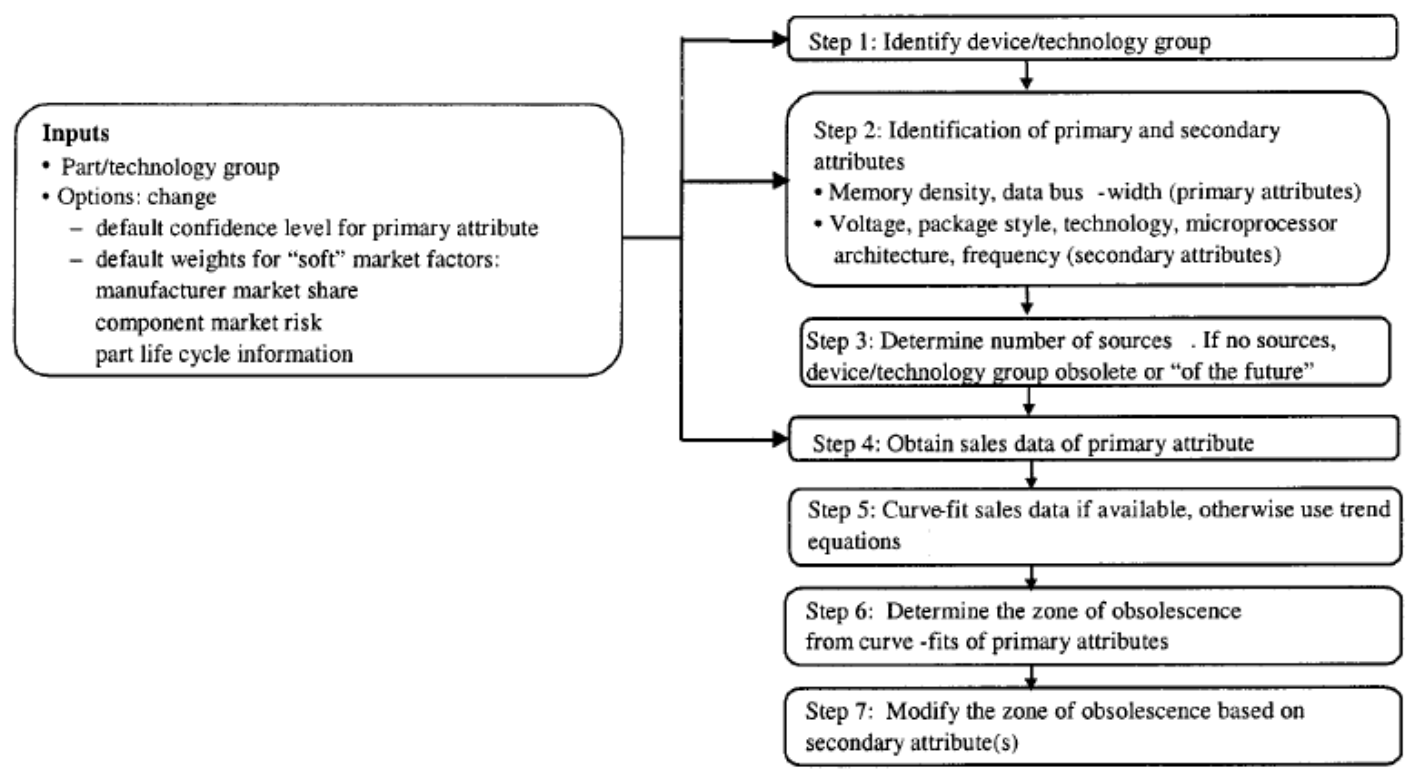

Figure 9 Life Cycle Forecasting Methodology (Adopted from [5])

\section{CONCLUDING REMARKS}

From what has been exposed throughout this paper, it can be concluded that it is necessary to study 'mitigation strategies' and 'resolution approaches' separately. The term 'mitigation' refers to the measures taken to minimise the impact or likelihood of having an obsolescence problem, whereas the term 'resolution' refers to the measures taken to tackle an obsolescence issue once it appears. Obsolescence risk can be mitigated by taking actions in three main areas: supply chain, design and planning. Within those, collaboration within the industry; standardisation of designs and modularisation that may promote the interchangeability of components; and the implementation of proactive actions to determine accurately the cost and impact of obsolescence, are the major means to minimise obsolescence risks. The resolution approaches are classified according to the replacement used into four categories: same 
component, FFF replacement, emulation and redesign. Among them, same component and FFF replacement are the most commonly used.

Most of the research described in the literature makes an attempt to determine:

How to reduce the risks of future component obsolescence;

$>$ How to react to occurrences of component obsolescence;

How to anticipate occurrences of component obsolescence;

\subsection{FUTURE RESEARCH CHALLENGES}

The research on obsolescence is growing; especially in the military and aerospace sectors because obsolescence is increasing becoming an important issue for sustainment-dominated systems. Most of the research carried out so far in the scope of obsolescence has been focused on the electronics components. However, very few studies have considered a holistic approach for obsolescence, taking into account the effects of obsolescence on mechanical components, materials, software, skills of the personnel and processes. It is suggested that a holistic study of the obsolescence topic will allow determining the whole impact that it has in a sustainment-dominated system across the whole life cycle and will identify ways to mitigate it.

Little attention has been given to software obsolescence so far. Indeed very few organisations in the defence industry are managing and costing software obsolescence. This area requires further research due to the current low level of understanding on software obsolescence and the impact that it has on the whole life cycle of "sustainment-dominated systems". It is also required to establish the links between hardware and software obsolescence. It is clear that they are integrated, so they can drive obsolete one another, but these relationships need to be explored further.

Finally, the move from traditional contracting for sustainment-dominated systems towards contracting for availability (CFA) is bringing the OEM and the customer to a new scenario in which they need to make accurate estimations of the obsolescence cost at the bidding stage. There is a need for a cost model to estimate the total cost that will be incurred mitigating and solving obsolescence issues. It should be capable of estimating the obsolescence cost even when information such as the BoM, the obsolescence predictions of a monitoring tool and the obsolescence management plan (OMP) are not in place yet. There is also a need for a systematic process for the development of fair contractual clauses to share the obsolescence 
risk between the OEM and the customer in a way that may benefit both parties equally. Additionally, there is a lack of formal approaches to measure the obsolescence management capability of OEMs and also a lack of studies on incentivising their suppliers for managing obsolescence.

\section{ACKNOWLEDGMENTS}

The authors would like to thank the UK Physical Sciences Research Council (EPSRC)/Cranfield IMRC for funding this project within the overall PSS-Cost research project.

\section{REFERENCES}

[1] Meyer, A., Pretorius, L., Pretorius, J. H. C., 2004. A model to manage electronic component obsolescence for complex or long life systems. Engineering Management Conference, 2004 Proceedings. 2004 IEEE International, vol. 3, pp. 1303 - 1309.

[2] Singh, P., Sandborn, P., Lorenson, D. and Geiser, T., 2002. Determining Optimum Redesign Plans for Avionics Based on Electronic Part Obsolescence Forecasts. Proc. World Aviation Congress, November 2002, Phoenix, AZ, SAE International.

[3] Pecht, M. G. and Das, D., 2000. Electronic part life cycle. IEEE Transactions on Components and Packaging Technologies, vol. 23, no. 1, pp. 190-192.

[4] Sandborn, P., 2007a. Designing for Technology Obsolescence Management. Proceedings of the 2007 Industrial Engineering Research Conference, 19-23 May 2007, Nashville, TN.

[5] Solomon, R., Sandborn, P. and Pecht, M., 2000. Electronic part life cycle concepts and obsolescence forecasting. Components and Packaging Technologies, IEEE Transactions on [see also Components, Packaging and Manufacturing Technology, Part A: Packaging Technologies, IEEE Transactions on], vol. 23, no. 4, pp. 707-717.

[6] Feldman, K. and Sandborn, P., 2007. Integrating Technology Obsolescence Considerations into Product Design Planning. Proceedings of the ASME 2007 International Design Engineering Conferences \& Computers and Information in Engineering Conference, Sept. 2007, Las Vegas, NV. 
[7] Howard, M. A., 2002. Component obsolescence - It's not just for electronics anymore. Proc.FAA/DoD/NASA Aging Aircraft Conference, San Francisco, CA, 16-19 Sept.

[8] Tryling, D. P., 2007. Planning for obsolescence. Electrical Apparatus, vol. 60, no. 4, pp. 23-24.

[9] Tomczykowski, W. J., 2003. A study on component obsolescence mitigation strategies and their impact on R\&M. Proceedings of Annual Conference on Reliability and Maintainability (RAMS), 27-30 Jan. 2003, IEEE, Tampa, FL, USA, pp. 332-338.

[10] Singh, P., Sandborn, P., Geiser, T. and Lorenson, D., 2004. Electronic part obsolescence driven design refresh planning. International Journal of Agile Manufacturing, vol. 7, no. 1, pp. 23-32.

[11] Hitt, E. F. and Schmidt, J., 1998. Technology obsolescence (TO) impact on future costs. Digital Avionics Systems Conference, 17th DASC, 31 Oct - 7 Nov. The AIAA/IEEE/SAE, vol. 1, no. A33, pp. 1-7.

[12] Josias, C., Terpenny, J. P. and McLean, K. J., 2004. Component obsolescence risk assessment. Proceedings of the 2004 Industrial Engineering Research Conference (IERC), 15-19 May.

[13] Condra, L., 1999. Combating Electronic Component Obsolescence by Using Common Processes for Defense and Commercial Aerospace Electronics. IECQ-CMC Avionics Working Group1, NDIA Paper document, September 1997.

[14] Feng, D., Sandborn, P. and Singh, P., 2007. Optimizing Lifetime Buy Quantities to Minimize Lifecycle Cost. MSc Thesis, University of Maryland, (available online http://www.lib.umd.edu/drum/bitstream/1903/6740/1/umi-umd-4217.pdf) (accessed on 8th April 2009).

[15] Meyer, A., Pretorius, L. and Pretorius, J. H. C., 2003. A management approach to component obsolescence in the military electronic support environment. South African Journal of Industrial Engineering, vol. 14, no. 2, pp. 121-136.

[16] Weaver, P. and Ford, M., 2003. ATE obsolescence solutions; costs and benefits [military equipment]. AUTOTESTCON 2003. IEEE Systems Readiness Technology Conference Proceedings, 22-25 Sept., pp. 623-628.

[17] Sandborn, P., Mauro, F. and Knox, R., 2007. A data mining based approach to electronic part obsolescence forecasting. 2007 IEEE Transactions on Components and Packaging Technologies, vol. 30, no. 3, pp. 397 - 401. 
[18] Torresen, J. and Lovland, T. A., 2007. Parts Obsolescence Challenges for the Electronics Industry. Design and Diagnostics of Electronic Circuits and Systems, 2007. DDECS'07. IEEE, 11-13 April, pp. 1-4.

[19] Adams, C., 2005. Getting a Handle on COTS Obsolescence, Avionics Magazine, (available online http://www.aviationtoday.com/av/categories/military/887.html) (accessed on 4th February 2009).

[20] Singh, P. and Sandborn, P., 2006. Obsolescence Driven Design Refresh Planning for Sustainment-Dominated Systems. The Engineering Economist, vol. 51, no. 2, pp. 115139.

[21] Madisetti, V., Jung, Y., Khan, M., Kim, J. and Finnessy, T., 2000. On upgrading legacy electronics systems: methodology, enabling technologies and tools. VHDL International Users Forum Fall Workshop, 2000. Proceedings, 18 - 20 Oct., Orlando, FL, USA, pp. 7-14.

[22] Singh, P. and Sandborn, P., 2005. Forecasting technology insertion concurrent with design refresh planning for COTS-based electronic systems. Reliability and Maintainability Symposium, 2005 Proceedings Annual, pp. 349-354.

[23] Romero, F. J., Roy, R., Shehab, E. and Wardle, P., 2009. Obsolescence Challenges for Product-Service Systems in Aerospace and defence Industry. The 1st CIRP Industrial Product-Service Systems (IPS2) Conference, 1st - 2nd April 2009, Cranfield University, UK.

[24] Bradley, M. and Dawson, R., 1999. Whole Life Cost: The Future Trend in Software Development. Software Quality Journal, vol. 8, no. 2, pp. 121-131.

[25] Livingston, H., 2000. GEB1: Diminishing Manufacturing Sources and Material Shortages (DMSMS) Management Practices. Proceedings of the 2000 DMSMS Conference, Jacksonville, Florida, 21-25 August.

[26] Redling, T. J., 2004. Considerations for upgrading aging military avionics systems with state-of-the-art technology. The 23rd Digital Avionics Systems Conference, 2004. DASC 04. 24-28 Oct., vol. 2, pp. 7.D.1- 7.1-7.

[27] Marion, R. L., Co, B. and Seattle, W. A., 2001. Mitigating COTS obsolescence in military test. AUTOTESTCON Proceedings, 2001. IEEE Systems Readiness Technology Conference, pp. 746-756.

[28] Luke, J., Bittorie, J. W., Cannon, W. J. and Haldeman, D. G., 1999. Replacement strategy for aging avionics computers. Aerospace and Electronic Systems Magazine, IEEE, vol. 14, no. 3, pp. 7-11. 
[29] Pope, S. M., Elliott, J. R. and Turbini, L. J., 1998. Designing for technological obsolescence and discontinuous change: an evaluation of three successional electronic products. pp. 286.

[30] Humphrey, D., Condra, L., Pendse, N., Das, D., Wilkinson, C. and Pecht, M. G., 2000. An avionics guide to uprating of electronic parts. IEEE Transactions on Components and Packaging. Technologies, vol. 23, no. 3, pp. 595-599.

[31] Barton, D.L. and Chawla, P., 2003.Designing systems for future obsolescence. Digital Avionics Systems Conference, 2003. DASC '03, vol.2, pp. 10.C.2-101-11, 12-16 Oct. 2003, IEEE, Indianapolis, IN, USA

[32] Craig, R. W., Co, B. and St Louis, M. O., 2002. A methodology for addressing support equipment obsolescence. Aerospace and Electronic Systems Magazine, IEEE, vol. 17, no. 5, pp. 20-25.

[33] Frank, B. and Morgan, R. L., 2007. Obsolescence mitigation and management of electronics test equipment. Autotestcon, 2007 IEEE, pp. 527-536.

[34] Mont, O., 2004. Product-service systems: Panacea or myth (Doctoral Dissertation thesis), The International Institute for Industrial Environmental Economics (IIIEE), Lund University: Lund, Sweden.

[35] Brewin, A., 2005. The Pb-free Minefield: A Guide to Mitigating Risk during the Transition to RoHS Compliance. 1st ed., COG International Ltd., UK.

[36] Sandborn, P., 2007b. Software Obsolescence - Complicating the Part and Technology Obsolescence Management Problem. IEEE Transactions on Components and Packaging Technologies, vol. 30, no. 4, pp. 886-888.

[37] Merola, L., 2006, The COTS software obsolescence threat, Fifth International Conference on Commercial-off-the-Shelf (COTS)-Based Software Systems, 2006. San Diego, CA.

[38] Sandborn, P. and Plunkett, G., 2006. The Other Half of the DMSMS Problem - Software Obsolescence. DMSMS Knowledge Sharing Portal Newsletter, vol. 4, no. 4, pp. 3 11.

[39] Dowling, T., 2000. Planning For Change With A Holistic View Of The System. Strategies to Mitigate Obsolescence in Defense Systems Using Commercial Components. vol. 22, 23-25 October 2000, Budapest, Hungary, RTO MP-072. 
[40] Dowling, T., 2004. Technology insertion and obsolescence. Journal of Defence Science, vol. 9 , no. 3, pp. 151-155.

[41] Herald, T., Verma, D. and Lechler, T., 2007. A Model Proposal to Forecast System Baseline Evolution due to Obsolescence through System Operation. Proceedings of 5th Annual Conference on Systems Engineering Research, Hoboken, New Jersey, 1416 March.

[42] Trenchard, M., 2003. The obsolescence minefield. IEE Review, vol. 49, no. 9, pp. 29-29.

[43] Sandborn, P., Mauro, F. and Knox, R., 2005. A Data Mining Based Approach to Electronic Part Obsolescence Forecasting. Proceedings of the 2005 DMSMS Conference, 11-15 April, Nashville, TN.

[44] Francis, L., 2006. Tackling obsolescence. Electronics Weekly, no. 2235, pp. 20-21.

[45] Leonard, J. V., Wolf, J., Stolinski, R., Co, M. D. D. A. and St Louis, M. O., 1988. Microcircuit parts obsolescence. IEEE Region 5 Conference, 1988:'Spanning the Peaks of Electrotechnology', pp. 229-231.

[46] Flaherty, N., 2005. New parts for old. IEE Review, vol.51, no.1, pp. 34-37.

[47] Manor, D., 2006. Addressing the Instrument Obsolescence Problem-Options and Solutions. Autotestcon, 2006. IEEE Systems Readiness Technology Conference, 1821 Sept, Anaheim, CA, USA, pp. 426-430.

[48] Sjoberg, E. S. and Harkness, L. L., 1996. Integrated circuit obsolescence and its impact on technology insertion definition for military avionics systems. Aerospace and Electronics Conference, 1996. NAECON 1996., Proceedings of the IEEE 1996 National, vol. 2, pp. 792 - 799.

[49] Baca, M., 2005. The third dimension in obsolescence management. Military \& Aerospace Electronics, pp. 15 - 18. (available online http://mae.pennnet.com/articles/article_display.cfm?article_id=236302) (accessed on 14th April 2009).

[50] Bray, O. H. and Garcia, M. L., 1997. Technology roadmapping: the integration of strategic and technology planning for competitiveness. PICMET '97, 27-31 July 1997, IEEE, Portland, OR, USA, pp. 25-28. 
[51] DoD, 2005. V-22 Obsolescence Management Plan. Department of Defense (DOD), Department of the Navy (DON), United States Air Force communities, U.S. (available https://acc.dau.mil/GetAttachment.aspx?id=46246\&pname=file\&aid=13738\&lang=en -US) (accessed on 10th April 2009).

[52] Neal, T. M., 2004. Obsolescence replacement-applied technology. AUTOTESTCON 2004 Proceedings, 20-23 Sept., pp. 58-61.

[53] Battersby, C., 2008. The Counterfeit Electronic Components Minefield: A Guide to understanding and avoiding Counterfeit Components. 1st ed., COG International Ltd., UK.

[54] MoD, 2004. Ministry of Defence Component Obsolescence Resolution Cost Metrics Study, QinetiQ and ARINC, UK. Available at http://www.nocweb.org/News/UK\%20Resolution\%20Cost\%20Metrics\%20Study\%20\%20Final1.pdf (accessed 12th January 2009).

[55] Pecht, M. and Humphrey, D., 2006. Uprating of electronic parts to address obsolescence. Microelectronics International, vol. 23, no. 2, pp. 32-36.

[56] Romero, F. J., 2007. Cost estimating process improvement within a manufacturing environment. (MSc Thesis), Cranfield University, UK.

[57] PRICE Systems, 2008. TruePlanning, available at: http://www.pricesystems.com (accessed 12th January 2009).

[58] Galorath, 2008. SEER-H. Available at: http://www.galorath.com/ (accessed 12th January 2009).

[59] Blackman, I. and Rogowski, R., 2008. The Obsolescence Tools Minefield: A Guide to Availability Monitoring. 1st ed., COG International Ltd., UK.

[60] Herald, T., Verma, D., Lubert, C. and Cloutier, R., 2008. An obsolescence management framework for system baseline evolution-Perspectives through the system life cycle. Systems Engineering, vol. 12, no. 1, pp. 1-20.

[61] Sandborn, P. and Singh, P., 2002. Electronic Part Obsolescence Driven Design Refresh Optimization. Proc. FAA/DoD/NASA Aging Aircraft Conference, September 2002, San Francisco, CA.

[62] Total Parts Plus, 2008. Parts Xpert \& Parts Plus. Available at: http://www.totalpartsplus.com/ (accessed 12th June 2008). 
[63] QinetiQ, 2008. Q-Star ${ }^{\mathrm{TM}}$. Available at: http://www.qtec.us (accessed 12th June 2008).

[64] MTI, 2008a. AVCOM. Available at: http://thedmsmscompany.com/avcom.asp (accessed 12th June 2008).

[65] MTI, 2008b. OASIS. Available at: http://thedmsmscompany.com/oasis.asp (accessed 12th June 2008).

[66] PartMiner, 2008. CAPSXpert, CAPS BOM Manager \& CAPS Forecast. Available at: http://www.partminer.com/ (accessed 12th June 2008).

[67] Herald, T. and Seibel, J., 2004. Technology Management Forecasting and Predictions for System of Interest Analysis. MARC, INCOSE, Reston, VA, pp. 1-14.

[68] Sandborn, P., 2004. Beyond reactive thinking-We should be developing proactive approaches to obsolescence management too!. DMSMS Center of Excellence Newsletter, vol. 2, no. 3, pp. 4 and 9.

[69] Porter, G. Z., 1998. An Economic Method for Evaluating Electronic Component Obsolescence Solutions, Boeing, Company White Paper. 